\title{
효과적인 SDGs 이행을 위한 KOICA 보건분야 중장기전략 수립에 대한 정책적 제언
}

목 차

I. 보건분야 SDGs 논의 흐름과 구조

1. 논의 흐름

2. SDGs에서의 보건

3. SDGs에서의 보건관련 목표현황

4. 이행방안 및 재원

II. KOICA 보건분야 중장기 전략의 역할과 SDGs

III. 보건분야 SDGs 비전과 KOICA 전략에 대한 제언

1. 보건분야 SDGs 비전 \& 가치

2. KOICA 보건전략의 비전, 미션, 핵심가치에 대한 제언

IV. 보건분야 SDGs 주요목표와 KOICA 전략에 대한 제언

1. 아동, 모성 등 취약계층 건강향상

2. 감염병, 비전염성 질병의 예방 및 치료

3. 약물남용 및 교통사고로 인한 사망감소

4. 성생식 보건 및 보편적 건강보장

5. 영양, 식수위생, 건강한 환경

6. 담배규제, 공중보건을 위한 지적재산권, 출생등록, 보건안보

V. SDGs 이행수단과 KOICA 전략에 대한 제언

1. 재원

2. 기술향상 및 공유

3. 국가계획 지원을 위한 역량강화

4. 다자간 파트너십

VI. 종합 제언 


\section{I. 보건분야 SDGs 논의 흐름과 구조}

\section{1. 논의 흐름}

새천년개발계획(MDGs)의 목표달성 시기를 2015년까지 정해 두면서 MDGs 이후의 Post-MDGs 의 Goal과 세부목표(target)를 어떻게 가져가야 할 것인가를 2010년부터 논의하기 시작하였다. 2010 년에서 2012년까지 65, 66차 UN총회와 연간 MDG 보고서를 중심으로 사전예비논의를 시작하였고, 2012 2013년까지 리우회의(2012.6월), UN 고위급패널 보고서(2013.5월)을 통해서 시민사회, 정부 등 다양한 의견을 수렴하였다. 2013 2014년에는 SDGs 공개작업반 회의, SDGs 고위급정치포럼에 서 의제를 구체화하고 목표와 세부목표의 초안을 제시하였다. 이러한 과정을 거쳐서 2015년 9월 70차 UN 총회에서 『Transforming our world: the 2030 Agenda for Sustainable Development』라는 공식문서를 채택하였다. ${ }^{1)}$

위와 같이 $\mathrm{SDGS}$ (지속가능목표)의 주요 의제를 논의하고 목표를 설정하고 세부목표에 대한 의견을 수렴하는 과정에서 $\mathrm{WHO}$ 를 비롯한 보건분야 주요 기관에서는 보건분야 주요목표를 어떻게 수립하고 반영할 것인가에 대해서도 주요 논의를 진행하였다. 2012년 WHO와 UNICEF가 공동 주관한 회의에 서는 건강의 사회결정적 요인인, 소녀의 교육, 건강 형평성, 양성 평등 등 인간의 권리와 존엄성을 지 켜야 한다는 원칙을 제시하였다. 또한, MDGs의 주요목표였지만 목표치를 달성하지 못하였던 모자보 건과 감염병에 대하여 지속적으로 포함되어야 한다는 입장을 표명하고, MDGs에는 세부목표에 포함 되지 않았지만 건강에 큰 영향을 끼치고 있는 고령화, 비전염성질병, 기후변화에 의한 건강변화, 인구 이동 및 난민에 대한 문제제기를 하였다. ${ }^{2}$

또한, 보건분야의 향후 15 년간 추구해야할 목표로서 보편적 건강보장(Universal Health Coverage)을 제시하고, 보편적 건강보장을 달성하기 위한 보건의료체계 강화, 건강권 보장, 보건의 료 형평성 강화가 주요 이슈로 포함되어야 함을 강조하였다. ${ }^{3)}$ 이와 함께 보건이 발전의 결과를 가늠하 는 지표이자 주요 이행수단임을 명시하며 보건에 관련된 이슈가 17 개의 전체목표에서 주류화 되어야 함을 강조하였다. ${ }^{4)}$

1) KOFID ISSUE brief Post-2015 개발의제란 무엇인가/한국 시민사회의 관점에서/

2) Informal Member State Consultation on Health in the Post 2015 Development Agenda 14 December 2012, World Health Organization, Executive Board Room, Summary Report

3) Positioning Health in the Post-2015 Development Agenda, WHO discussion paper, October 2012

4) Draft, WHO, January 2015, 1, Towards a monitoring framework with targets and indicators for the health goals of the post-2015 Sustainable Development Goals 


\section{SDGs에서의 보건}

UN 70차 총회 공식문서 『Transforming our world: the 2030 Agenda for Sustainable Development』는 서문(Preamble), 선언(Declaration), 지속가능개발목표(Sustainable Development Goals), 이행수단(Means of implementation), 후속조치 및 평가(Follow up and review) 로 총 91항으로 이루어져 있다. ${ }^{5)}$

91개 항 중에서 health 또는 healthy 라는 언급은 총 33회 나타나고 있다. 보건(health)관련 주요 언급을 살펴보면 서문의 비전 7항에서 신체적, 정신적, 사회적 well-being과 건강을 보장하기 위하 여 보건의료와 사회적 보호에 대한 보편적인 접근을 보장한다고 명시하고 있으며, 오늘날 세계에 대 한 16 항에서는 보건의료에 관련된 MDGs에 큰 진전이 있었지만 그 성과가 불평등하게 이루어졌다 고 지적하고 있다. 새로운 아젠다 제시인 26 항에서는 보편적 의료보장을 달성하여 "No one must be left behind' 원칙을 지키고, 성생식보건, 말라리아, HIV/AIDS, 결핵, 간염, 신종 감염병, 비전염성 질병, 정신질병 등 다양한 의제를 제시하였다. 34 항에서는 도시, 환경, 기후변화로 인한 건강 문제에 대하여 언급하였으며, 37항에서는 스포츠의 건강에 대한 기여를 언급하였다.

\section{SDGs에서의 보건관련 목표현황}

$\mathrm{SDGS}$ 에서 보건관련 주요 목표는 SDG 3에 주로 포함되어 있으며, 그 외에 영양과 관련된 것은 SDG 2의 세부목표 2.1과 2.2, 식수 위생과 관련된 것은 SDG 6의 세부목표 6.1, 6.2, 6.b에서 이야기 되고 있다. 또한 SDG 5의 세부목표 5.6에는 성생식 보건 향상을 제시하고 있으며, SDG 12 의 세부목 표 12.4에는 대기, 수질, 토양 오염에 의한 건강 부작용에 대한 목표를 언급하고, SDG 16의 세부목표 16.9 에는 출생 등록을 포함한 법적 지위 부여를 논하고 있다.

SDG 3 를 세부목표별로 살펴보면 9개의 세부목표와 4개의 이행목표로 구성되어 있으며 9 개의 세 부목표는 신생아, 아동, 모성 등 보건에 대한 취약계층을 위한 세부목표 3.1 모성건강, 3.2 아동건강, 질병을 예방하고 관리하기 위한 세부목표 3.3 감염병, 3.4 비전염성질병, 건강한 삶을 위협하는 외부 요소인 약물남용, 교통사고, 공해와 오염을 줄이기 위한 세부목표 3.5 약물남용, 3.6 교통사고, 3.9 공해와 오염, 필수보건의료 서비스의 보장을 위한 세부 목표 3.7 성생식 보건서비스 3.8 보편적 의료 보장을 설정하였다. 또한 4 개의 이행목표는 3.a 담배규제, 3.b 의약품 지적재산권, 3.c 보건의료인 력, 3.d 보건안보를 제시하였다. ${ }^{6)}$

5) Seventieth session, Resolution adopted by the General Assembly on 25 September 2015

6) 지속가능개발목표 수립현황과 대응방안 2015. 7 KOICA 


\section{〈표 1〉SDGs 중 보건관련 세부목표 ${ }^{7)}$}

2.12030 년까지 기아종식, 빈곤층과 취약계층, 영유아를 포함한 모든 사람들에 대한 연중 안전 하고, 고영양 의, 충분한 식량 공급 보장

2.25 세 미만 아동의 발달저해와 신체쇠약을 방지하도록 2025년까지 국제적으로 합의된 세부 목표 달성을 포 함한, 2030년까지 모든 형태의 영양실조 종식과 청소년기 소녀, 임산부, 수유부, 노인의 영양적 필요 고려

3.12030 년까지 전 세계 모성사망비를 70/10만 live birth 이하로 감소

3.2 2030년까지 신생아와 아동의 예방 가능한 죽음을 종식시켜서, 신생아 사망률을 12/1000 live birth 이하 로, 5 세 이하 아동사망율을 $25 / 1000$ live birth 이하로 감소

3.3 2030년까지 AIDS, 결핵, 말라리아, 소외열대질병의 유행을 종식시고, 간염, 수인성 질병과 다른 감염성 질병의 확산 방지

3.42030 년까지 정신건강 증진과 비전염성질병 예방과 치료로 비전염성질병으로 인한 조기 사망을 $1 / 3$ 로 감소

3.5 마약과 알코올을 포함한 약물남용의 예방과 치료 강화

3.6 2030년까지 교통사고로 인한 전 세계 사망과 상해를 $1 / 2$ 이하로 감소

3.72030 년까지 가족계획을 포함한 성생식 보건 서비스에 보편적 접근 보장, 생식보건의 국가 전략 및 프로 그램에 통합

3.8 의료비의 재정위험으로부터 보호, 양질의 필수의료서비스 접근, 안전하고 효과적이며 양질의 비용지불가 능한 필수의약품 및 백신 접근 등 보편적 건강보장 달성

3.9 2030년까지 유해물질, 공기, 물, 토양의 공해와 오염으로 기인한 사망과 질병의 감소

3.a 모든 국가에서 $\mathrm{WHO}$ 의 담배규제기본협약의 이행 강화

3.b 개발도상국에 영향을 주는 전염성, 비전염성 질병을 위한 백신과 약품의 개발과 연구 지원, 무역관련 지 적재산권 협정과 공중보건에 관한 도하선언에 따라 값싼 의약품과 백신에 대한 접근 제공

3.c 개발도상국 의료 인력의 고용, 발전, 훈련, 유지를 위한 보건재정의 확충

3.d 국가적, 국제적 보건 위험 관리, 위험 감소, 조기 경보를 위한 모든 국가의 역량강화

5.6 국제인구개발회의(International Conference on Population and Development, ICPD)와 북경행동강 령에 부합하는 성생식 보건과 성생식 권리에 대한 모든 사람의 동등한 접근 보장

6.12030 년까지, 안전한 식수에 대한 보편적이고 형평성 있는 접근성 보장

7) 지속가능개발목표 수립현황과 대응방안 2015. $7 \mathrm{KOICA(전체} \mathrm{세부목표} \mathrm{중} \mathrm{보건분야} \mathrm{저자} \mathrm{편집)}$ 


\section{2 안전 식수를 이용할 수 있는 인구율(\%)}

\section{6.b 물과 위생 관리 향상에 지역사회의 참여 강화}

12.42020 년까지 인류의 건강과 환경에 미칠 악영향을 최소화하기 위해, 국제협약에서 합의한 바와 같이 물 질의 분해 주기에 따른 환경적으로 건전한 화학물질 및 폐기물 관리 달성과 이들의 공기· 물· 토양 배 출 대폭 경감

16.9 2030년까지 모든 사람에게 법적 지위 부여(출생등록 포함)

\section{4. 이행방안 및 재원}

UN 70차 총회 공식문서 『Transforming our world: the 2030 Agenda for Sustainable Development」의 60-91항에는 지속가능개발 목표의 이행방안과 재원을 위한 후속조치와 평가에 대 해서 기술되고 있다.

17 개의 목표와 169 개의 세부목표를 이행하기 위해서 개발재원의 다양화, 기술의 공유 향상, 역량 강화, 무역을 통한 개발, 제도일관성, 파트너십 증진, 데이터 모니터링에 대한 책무성을 이행수단으로 서 강조하고 있다. 또한, 국가적 차원에서 지역적 차원에서 글로벌한 차원에서 목표에 대한 성과관리 와 평가방법에 대하여 기술하여 각 주체의 책무성을 강조하고 있다.

\section{KOICA 보건분야 중기 전략의 역할과 SDGs}

$\mathrm{KOICA}$ 에는 $\mathrm{KOICA}$ 의 전체적인 방향성을 제시하고있는 ' $\mathrm{KOICA}$ 중기전략'과, 다자협력 전략, 민 관협력 전략과 같이 사업형태별 추진방안을 제시하고 있는 '사업형태별 전략', 그리고 아프리카 전략, 아시아 전략과 같이 지역적 추진방안을 제시하고 있는 '지역별 전략'이 날줄과 씨줄처럼 얽혀서 정책 적 방향을 제시하고 있다. 이러한 상황에서 보건분야 중기 전략은 대내외적으로 다음 세 가지 역할을 수행할 것을 요구받고 있다. 첫째는 KOICA 보건 프로그램을 통해 국제보건에서의 비전과 미션을 제 시해주는 '방향제시'의 역할을 하고자 한다. 하지만 지금까지 KOICA 보건분야 중기전략에 제시된 비 전과 미션은 '개발도상국 건강수준 향상을 통한 국제사회 안전과 번영에 기여'(2008-2010), '건강한 삶을 통하여 지속가능한 발전에 기여'라는 명확하지 못한 비전을 제시하고 있다. KOICA 보건분야 프 로그램을 통해서 효과적인 SDGs 이행을 위해서는 전략의 비전과 미션을 SDGs에서 강조하고 있는 가 치와 비전, 보건분야 주요 이슈와 연계시켜서 논리적 정당성을 확보할 필요가 있다. 둘째는 프로젝트 
사업, 다자협력 사업, 민관협력 사업, 역량개발 사업, 봉사단 사업 등 다양한 방법으로 행해지고 있는 보건분야 프로그램의 성과를 관리하는 틀을 제시하고 성과관리할 수 있는 가이드라인을 제시하는 것 이다. 하지만 KOICA 보건전략(2008-2010)과 KOICA 보건전략(2011-2015)에서는 성과관리의 틀 로서 역할을 제대로 하지 못하였다. SDGs에서는 보건분야의 Goal, 세부목표, 이행목표 그리고 각 목표별 지표를 설정하고 그 이행수단과 평가를 강화하고 있어 $\mathrm{KOICA}$ 보건전략에도 성과관리의 틀 을 제시하고 각 형태별로 이루어지고 있는 보건분야 사업의 성과를 KOICA 기관 차원의 성과로 모아 낼 수 있도록 전략에서 제시되어야 한다. 마지막으로 다양한 기관과 협력국에서 제안하는 제안서 중 에서 KOICA가 더 우선순위를 두고 선택과 집중해야 할 분야를 제시해 주는 역할을 요구받는다. 하 지만 지난 두 번의 전략에서는 모든 분야의 보건 이슈를 포함하는 포괄적인 프로그램 목표를 제시함 으로써 협력국의 특수한 상황과 요청을 반영하는 것에는 유의한 역할을 해왔으나 다양한 제안서 중에 서 선택과 집중하여 더 많은 성과를 낼 수 있는 가이드라인을 제시해 주지 못하였다. SDGs에서는 20 여개 가까운 세부목표를 제시하여 60 여개 가까운 보건 이슈를 주요 목표와 지표화하여 관리하고자 한 다. $\mathrm{KOICA}$ 의 보건중기 전략에는 모든 중요한 보건이슈 중에서 $\mathrm{KOICA}$ 가 잘 할 수 있고 더 집중해야 할 분야를 제시하여야 한다. ${ }^{8)}$

\section{III. 보건분야 SDGs 비전과 KOICA 전략에 대한 제언}

\section{1. 보건분야 SDGs 비전 \& 가치}

$\mathrm{SDGs}$ 는 서문에서 비전 및 가치로서 5P(People, Planet, Prosperity, Peace, Partnership)를 제 시하고 인간의 존엄성, 지속가능한 지구, 경제사회 기술적 번영, 포용적인 사회를 위한 평화, 파트 너십을 제시하였다. 이러한 다섯 가지 가치를 반영하여 보건분야의 SDGs 비전으로는 7항에서 “A world with equitable and universal access to quality education at all levels, to healthy care and social protection, where physical, mental and social well-being are assured.” 이라고 표 현하고 있다. 또한 26항에서는 “To promote physical and mental healthy and well-being, and to extend life expectancy for all, we must achieve universal healthy coverage and access to quality healthy care. No one must be left behind" 마지막으로 SDG 3의 Goal로서 "Ensure healthy lives and promote well-being for all at all ages” 나타내고 있다. 위에 언급한 7항, 26항,

8) KOICA 보건중기 전략 평가 2015. $12 \mathrm{KOICA}$ 
Goal 3 를 보았을 때 보건분야의 주요 가치로서 모든 사람이 보편적 건강보장을 누릴 권리가 있고 이 를 달성하기 위해서 형평성이 보장된 보건의료 서비스 접근성 향상을 강조하고 있다. ${ }^{9)}$

\section{KOICA 보건전략의 비전, 미션, 핵심가치에 대한 제언}

$\mathrm{KOICA}$ 의 보건전략은 KOICA가 왜 보건 프로그램을 실행하는 지에 대한 이유를 제시할 필요가 있 으며 그 이유가 포함된 비전, 미션, 핵심가치를 제시해야 한다. 이러한 비전에는 SDGs의 핵심가치 로 제시된 '인간의 존엄성'을 향상하기 위한 수단으로서의 보건의료와 그 결과를 나타내는 지표로서의 건강을 명시하고 $\mathrm{KOICA}$ 의 보건 프로그램이 $\mathrm{SDGs}$ 의 보건분야 핵심가치인 '인간의 존엄성'과 연계될 수 있도록 표현되어야 한다. 또한, SDGs 보건분야의 비전인 보편적 건강보장에 대해 기여하는 것을 $\mathrm{KOICA}$ 보건전략의 미션으로 삼아 KOICA 보건프로그램을 실행하는 목표가 '보편적 건강보장'을 달 성하기 위함임을 명시한다면 효과적인 SDGs 이행을 위해서 논리적 정당성을 확보할 수 있을 것으로 보인다. 마지막으로 SDGS에서 제시된 보건분야 핵심가치로서 형평성을 $\mathrm{KOICA}$ 보건분야 중기전략 의 핵심가치로 삼아 건강불평등을 완화할 수 있도록 프로그램에 적용하는 것이 필요하다.

\section{IV. 보건분야 SDGs 주요목표와 KOICA 전략에 대한 제언}

\section{1. 아동, 모성 등 취약계층 건강향상}

$\mathrm{SDGS}$ 에서는 보건분야의 주요목표로 세부목표 3.1과 3.2에서 아동과 모성의 건강향상을 제시 하고 있다. 이 목표는 MDGs에서도 Goal로 제시된 바 있으며, 향후 15 년 동안에도 주요 이슈로 제 기될 가능성이 높다. 또한, 대한민국은 무스코카 이니셔티브에 참여하고 있으며, 국제빈곤퇴치 기 여금을 활용하여 모자보건 initiative 프로그램을 추진 중이며 KOICA는 PMNCH(Partnership for Maternal Neonatal Child Health)에 참여하고 있다. 이러한 점을 고려하였을 때 KOICA 보건중기 전략에는 모자보건에 대해서 선택과 집중하여 더 확실한 기여를 할 필요가 있다. 이러한 기여를 하기 위해서 모자보건 관련 국제사회 활동을 늘리고, SDGs 모자보건 관련 지표와 $\mathrm{KOICA}$ 보건전략의 모 자보건 프로그램의 지표를 연동하여 제시할 필요가 있다.

9) Seventieth session, Resolution adopted by the General Assembly on 25 September 2015 


\section{2. 감염병, 비전염성 질병의 예방 및 치료}

$\mathrm{SDGs}$ 에서는 감염병에 대한 세부목표 3.3에서 HIV/AIDS, 결핵, 말라리아, 간염, 수인성 전염병 등 다양한 감염병의 예방 및 치료에 대하여 목표를 제시하고 있다. 이러한 기존 감염병뿐만 아니라 신 종감염병의 예방, 대응, 감시도 거론하고 있다. 이는 기존의 KOICA 보건전략에서 제시하고 있는 감 염병에 대한 전략목표, 프로그램 등을 고려하고, 최근 GHSA(Global Health Security Agenda)에 기 여하기 위한 대한민국의 initiative인 Safe life for all을 고려할 때 KOICA 보건 중기 전략의 중요 프 로그램으로 고려할 필요가 있다.

비전염성 질병은 세부목표 3.4 로 고혈압, 당뇨, 암, 심혈관계 질환, 정신 질병 등을 관리하도록 제 시하고 있다. MDGs에는 포함되지 않았으나 SDGs에 새롭게 제시된 점, 또한, 선진국뿐만 아니라 개 발도상국에서도 그 질병부담이 증가하고 있으며 상위권을 차지하고 있다는 점에서 $\mathrm{KOICA}$ 에서도 주 목해야할 이슈이다. 하지만 국내의 당뇨나 고혈압에 대한 질병부담이 여전히 높은 시점에서 KOICA 의 보건분야 중점 프로그램으로 비전염성 질병에 선택과 집중하는 것은 대한민국 국민의 개발협력에 대한 눈높이를 고려하여 신중하게 결정하는 것이 필요하다.

\section{3. 약물남용 및 교통사고로 인한 사망감소}

$\mathrm{SDGS}$ 에서 건강분야 세부목표로 새로이 제시한 3.5 약물남용과 3.6 교통사고 이슈는 그 동안 보건 분야 개발협력에서 중요하게 다뤄지지 않았던 분야이며, 보건에 특화된 이슈라기보다는 거버넌스 등 타 분야와 다양하게 연결된 분야이다. 그 동안 $\mathrm{KOICA}$ 의 이 분야에 대한 활동은 미미 하였고 이러한 새로운 분야에 대한 ODA활동에 대해서 국내적 관심을 환기하는 것이 쉽지 않을 것을 고려할 때 이 목 표에 대해서는 국내의 관심을 환기하는 수준에서 적용하는 것이 적절하다.

\section{4. 성생식 보건 및 보편적 건강보장}

$\mathrm{SDGs}$ 에서는 세부목표 3.7 성생식 보건, 세부목표 3.8 의 보편적 건강보장, 세부목표 5.6 성생식 보건 보편적 접근에서 강조되고 있다. 보편적인 건강보장은 SDGs의 보건분야 핵심가치일 뿐만 아니 라 주요목표로서 국제적, 국내적으로도 주요한 이슈로서 작용하고 있다. 또한 성생식 보건이 젠더관 련 이슈이자 성생식 권리의 인권에 관한 이슈로서 $\mathrm{KOICA}$ 가 조금 더 선택과 집중할 필요가 있다. 또 한 보편적 건강보장을 $\mathrm{KOICA}$ 보건 프로그램의 철학적 가치의 수준, 전략적 방향에 대한 수준, 프로 젝트 수준에서의 적용 방안을 고민하여 각각의 수준에서 보편적 건강보장을 반영해야 한다.

예를 들면 가치, 철학적 수준에서 보편적 건강보장을 반영하기 위해서 건강권을 보장하는 것을 포 
함하여 $\mathrm{KOICA}$ 보건전략의 비전으로 제시하는 것이 필요하며, 전략적 방향에 있어서도 취약계층을 포함한 모든 사람이 보건의료 서비스에 접근할 수 있도록 형평성을 강조하는 것이 필요하다. 또한 프 로그램 수준에서도 보편적 건강보장을 달성하기 위한 보건의료 재정을 포함한 시스템적 접근이 필요 하다.

\section{5. 영양, 식수위생, 건강한 환경}

영양은 SDG 2에 제시되며 농업과 보건의 다분야적 접근이 요구되며, 식수위생은 SDG 6에 제시되 며 환경과 보건의 다분야적 접근이 필요하다. 또한 유해물질, 환경오염 등은 SDG 3과 SDG 12 에 모 두 포함되어 있다. 이렇듯 한 이슈의 해결을 위하여 여러 분야의 종합적인 접근은 SDGs의 특징이기 도 하다. 영양과 식수위생은 그 동안 $\mathrm{KOICA}$ 보건 프로그램에서 많은 부분을 차지하는 이슈였고 국제 사회에서의 중요도도 지속적으로 증가하고 있어 $\mathrm{KOICA}$ 가 보다 더 선택과 집중하여 SDGs의 달성에 기여할 수 있는 분야라고 여겨진다. 하지만 유해물질, 환경오염 등 건강한 환경 프로그램은 최근 실 내 공기오염 감소를 위해 다양한 프로그램이 개발되고 있지만 아직 KOICA 내에서는 활발하지 않아 $\mathrm{KOICA}$ 보건전략에서는 중점 프로그램이 아닌 일반 프로그램으로 포함하여 관리하는 것이 적절할 것 으로 보인다.

\section{6. 담배규제, 공중보건을 위한 지적재산권, 출생등록, 보건안보}

$\mathrm{SDGs}$ 에서는 세부목표 이외에 보건이슈에 대한 협약과 규제 등을 통해 건강한 삶을 향상시 킬 있도록 이행목표를 제시하고 있다. 그 중 담배규제에 대해서는 담배규제기본협약(Framework Convention on Tobacco Control)의 이행확산, 무역관련 지적재산권 협정과 공중보건에 대한 도하 선언(Doha Declaration on the TRIPS Agreement) 등 공중보건에 큰 영향을 끼치는 협약의 준수 및 확산을 강조하고 있다. 이러한 이슈에 대해서 $\mathrm{KOICA}$ 는 프로그램 수준에서 활동하는 것은 어렵겠 지만, 다양한 국제보건 회의 및 컨퍼런스에서 이슈를 꾸준히 제기하는 방식으로 기여하는 것을 고려 해 볼 수 있다.

\section{SDGs 이행수단과 KOICA 전략에 대한 제언}

$\mathrm{SDGs}$ 에서는 17 개 목표와 169 개 세부목표를 이행하기 위한 수단으로 서 재원 조달방안, 기술향상 및 공유, 국가계획 지원을 위한 역량강화, 개발을 위한 무역, 정책과 제도의 일관성, 다자간 파트너십, 
데이터 모니터링 및 책무성을 제안하고 있다.

\section{1. 재원}

재원조달 방안으로는 전통적인 ODA자금 뿐만 아니라 협력국의 국내 세금 및 공공수익, 공공투자 등을 포함하여 재원을 마련하고자 한다. $\mathrm{KOICA}$ 의 보건전략에는 이러한 다양한 재원 활용의 가능성 을 반영하여 한국 국민의 세금을 기본으로 다양한 투자 및 외부재원과 상승효과가 발생할 수 있는 협 력방법을 모색하는 것이 필요하다.

\section{2. 기술향상 및 공유}

$\mathrm{SDGS}$ 에서는 선진국에서 개발도상국의 기술공유뿐만 아니라, 남남협력, 삼각협력을 통해 과학기 술 혁신역량을 강화하고 적정기술의 보급을 강조하고 있다.

$\mathrm{KOICA}$ 의 보건전략에는 한국의 보건의료 관련 기술과 지식을 개발도상국과 공유할 수 있는 프로 그램을 설정하는 것이 필요하며, 혁신적인 기술을 통해 보건문제를 해결할 혁신적인 아이디어 공모 프로그램 등에 더 적극적으로 참여하는 것도 필요하다.

\section{3. 국가계획 지원을 위한 역량강화}

$\mathrm{SDGs}$ 에서는 개발도상국의 국가계획을 지원하기 위하여 역량강화를 지원할 것을 제안하고 있다.

$\mathrm{KOICA}$ 보건전략에는 협력국이 스스로 보건 프로그램을 기획, 운영, 모니터링할 수 있는 다양한 보건분야 PBA 프로그램을 도입할 수 있도록 제도적 장치를 반영해야 한다.

\section{4. 다자간 파트너십}

$\mathrm{SDGs}$ 에서는 지속가능개발을 위한 글로벌 파트너십을 향상하고 특히 공공, 민관, 시민사회 파트너 십을 증진할 것을 제안하고 있다.

지난 2번의 KOICA 보건전략에는 KOICA 보건분야 프로그램을 운영하기 위하여 파트너십 방안에 대해서는 제시하지 못하였다. 하지만 핵심 보건 프로그램의 주요 활동기관과의 다자간 파트너십 방안 과, 다변화 되고 있는 국제보건 활동기관과의 전략적 파트너십 방안을 수립하고 전략에 포함하는 것 이 필요하다. 


\section{5. 평가 및 책무성}

『세계의 변혁:2030 지속가능개발의제」에서는 제시하지 못하였지만, UN은 2016년 3월까지 169개 세부목표에 대한 지표와 목표치를 발표할 예정이다. 이렇게 설정된 지표와 목표치는 각 국가, 지역, 글로벌한 수준에서 모니터링되고 평가될 예정이다. 또 이러한 자료를 확보하고 분석하여 공유할 것을 개별 국가 및 모든 기관의 책무성으로 표현하고 있다.

$\mathrm{KOICA}$ 도 이러한 성과관리 및 평가에 대한 책무성을 이행하기 위하여 보건전략에는 다음 세 가지 사항을 반영하는 것이 필요하다. 첫째, $\mathrm{KOICA}$ 주요 보건 프로그램의 성과관리 틀을 공유할 필요가 있다. 이렇게 공유된 틀을 통하여 개별 프로젝트가 전체 $\mathrm{KOICA}$ 보건 프로그램에서 어떠한 위치를 차 지하는지 알 수 있도록 할 필요가 있다. 둘째, 제시한 성과관리 틀을 통하여 양자 간 프로젝트 사업, 다자간 사업, 역량개발사업, 민관협력 사업, 봉사단 파견사업의 여러 형태로 이루어지고 있는 보건분 야 프로그램의 성과를 $\mathrm{KOICA}$ 기관 차원의 성과로 모아낼 수 있어야 한다. 셋째, $\mathrm{KOICA}$ 의 성과를 적 극적으로 협력국과 국내외 보건분야 개발협력 전문가들과 공유할 수 있도록 명시화 하여야 한다.

\section{VI. 종합 제언}

향후 15 년간 전 세계가 함께 달성하기 위해 노력할 지속가능개발목표 SDGs가 제안되었다. KOICA 도 지난 두 번의 보건중기전략을 바탕으로 2016-2020년까지 활용될 새로운 보건중기전략을 작성하 는 중이다. 효과적인 SDGs 이행을 위한 $\mathrm{KOICA}$ 보건전략을 수립하기 위해서는 크게 세 가지 관점에 서 SDGs의 내용이 KOICA 보건전략에 반영되어야 한다. 첫째는 보건분야 SDGs의 주요 비전 및 가 치인 '인간의 존엄성', ‘보편적 건강보장'을 $\mathrm{KOICA}$ 보건전략의 비전 및 미션에 반영하는 것이 필요하 다. 둘째는 SDGS에서 보건분야 목표 및 세부목표로 제시된 것을 $\mathrm{KOICA}$ 의 개별 프로그램으로 반영 해야 하며, 이 중 KOICA의 현황, 국내외의 상황, 대한민국의 initiative를 고려해서 핵심 프로그램으 로 설정하여 모든 것이 포함된 SDGs의 보건목표에서 KOICA가 더 기여할 수 있는 부분을 설정해야 한다. 셋째는 SDGs의 보건분야 목표를 이행하기 위하여 성과관리와 파트너십을 위한 구체적인 실행 계획과 가이드라인을 제시할 필요가 있다. 


\section{〈참고문헌〉}

이성훈. 2014. "KOFID ISSUE brief Post-2015 개발의제란 무엇인가 한국 시민사회의 관 점에서" ${ }^{\prime} \mathrm{KOFID} \mathrm{ISSUE} \mathrm{brief』.} \mathrm{서울:} \mathrm{KOFID}$

한국국제협력단. 2015. “지속가능개발목표 수립현황과 대응방안”. 성남: 한국국제협력단 오충현, 박유애, 백지원. 2015. "KOICA 보건중기 전략(2011-2015) 이행현황 평가 보고서” 성남: 한국국제협력단 (발간 예정)

WHO. 2012. “Informal Member State Consultation on Health in the Post 2015 Development Agenda”. WHO 2012. "Positioning Health in the Post-2015 Development Agenda". WHO 2015. "Towards a monitoring framework with targets and indicators for the health goals of the post-2015 Sustainable Development Goals”. WHO

UN, 2015. "Transforming our world: the 2030 Agenda for Sustainable Development" 